\title{
Occupational stress, work-home interference and burnout among Belgian veterinary practitioners
}

\author{
Hansez I. ${ }^{1}$, Schins, F. ${ }^{1}$ and Rollin, F. ${ }^{2}$ \\ ${ }^{1}$ University of Liège, Faculty of Psychology, Work Psychology Department, Liège, Belgium \\ 2 University of Liège, Faculty of Veterinary Medicine, Clinic for Ruminants, Liège, Belgium
}

\begin{abstract}
There have been few formal studies on stress in veterinary surgeons and, in the rare studies available, stress is not examined jointly through the levels of job strain and job engagement, the sources of stress in the issue of work environment and the work-home interference. The authors' goal in this study was to analyse job engagement, job strain, burnout, work-home interference and job stress factors among 216 Belgian veterinary surgeons. Rural practice was compared to small animal and mixed activity. The mean job strain and job engagement level in veterinary surgeons was not higher than what we found in other working populations. However, $15.6 \%$ of the group were found to be suffering from high burnout. Rural practitioners had a lower level of job engagement than small animal veterinary surgeons. These small animal practitioners had a lower level of job strain than the mixed practitioners. The level of burnout did not differ significantly across the three types of activity. In comparison to other Belgian and Dutch workers, veterinary surgeons perceived more negative workhome interference. Bovine and mixed practitioners were the most concerned with this problem. The two most important sources of stress reported by bovine practitioners were relations to farmers and working time management (including emergencies and availability).
\end{abstract}

Key Words: burnout, job engagement, job stress, veterinary surgeons, work-home interference

$\underline{\text { Irish Veterinary Journal }}$ Volume 61 Number 4 233-241, 2008

\section{Corresponding author:}

Isabelle Hansez

University of Liège, Faculty of Psychology, Work Psychology

Department, Bd du Rectorat, 5 (B32)

B4000, Liège, Belgium

Tel: +32 $43662092(2013)$

Fax: +3243662944

Email: ihansez@ulg.ac.be

\section{Introduction}

\section{Stress in veterinary surgeons}

Numerous studies have been conducted about stress and burnout in the healthcare professionals including doctors (Wolfgang, 1988), nurses (Firth and Britton, 1989; Revicki and May, 1989; Garrett and McDaniel, 2001) and dentists (Myers and Myers, 2004). However, there are few formal studies about stress in veterinary surgeons. Is it linked to a lack of interest in the subject or to the fact that veterinary surgeons are not concerned with problems associated with stress? According to the Belgian Veterinary Surgeon Association, and taking experiences gathered from veterinary surgeons into account, the first proposition seems to best fit the situation.

Before looking at the literature about occupational stress and work-home interference in veterinary surgeons, some basic conceptual clarifications are needed. When measuring occupational stress, one must be careful not to confound the effects of stress or outcome variables and the sources of stress or the antecedent variables. To date, the literature suggests that there is no clear evidence of a common pattern of physiological effects of stress for all the sources of stress (Klein, 1996). For that reason, the authors' approach to stress refers to a more transactional model (Mackay and Cooper, 1987; Lazarus, 1995) based on cognitive theories and coping that emphasise the interaction between environmental demands and individual responses (Nyssen et al., 2003). We will define stress as "a process by which job demands are appraised by the worker as exceeding their own resources which results in undesirable health consequences" (De Keyser and Hansez, 1996 p133). According to the literature, the effects of stress can be mitigated by having high control (Karasek, 1979), high satisfaction (Payne, 1987) and high work commitment (Meyer and Allen, 1997) in a job. The study of stress at work should thus examine the effects of stress (outcome variables, e.g., job strain, burnout, job engagement) together with the sources of stress and situational factors which may decrease stress levels by improving an individual's ability to cope with a stressful situation (Nyssen et al., 2003). 'Work-home interference' (WHI) is defined in "a process in which a worker's functioning (behaviour) in one domain (e.g., home) is influenced by (negative or positive) load reactions that have built up in the other domain (e.g., work)" (Geurts et al., 2005 p322).

Results from previous empirical research give support to some sources of stress inherent to the situation of veterinary surgeons. Long working hours, for example, are often cited in the literature. Excessive workload can represent a real threat to practitioners' health and safety, 
even more so than a feeling of too much job involvement or a lack of job satisfaction (Houston and Allt, 1997; Sparks et al., 1997; Trimpop et al., 2000; Phillips et al., 2001; Rejula et al., 2003). Ethical problems (Sanders, 1995; Schneider, 1996) and euthanasia are also job stress factors. Veterinary surgeons facing the act of euthanasia involving pets they have grown fond of may suffer from emotional conflict and ambivalent feelings (Arluke, 1991). Relationships with clients also represent an important source of stress. A small percentage of clients complain, and new practitioners must be highly skilled in communicating with people to maintain proper relationships with clients (Bledsoe, 1991; Russel, 1994; Kogan and McConnell, 2001). Moreover, occupational risks (Trimpop et al., 2000) are high in this profession, especially in relation to injuries inflicted by animals. Some risks are also due to car accidents during work. However, it is hard to get reliable data about this, since veterinary surgeons can sometimes deal with injuries by themselves (Langley et al., 1995; Poole, 1998; Gabel and Gerberich, 2001). Another professional risk concerns diseases related to animal care (allergies, zoonoses, illnesses due to radiation, drugs and pesticides, etc.) or musculoskeletal disorders due to uncomfortable working positions, above all in rural practice (Jeyaretnam et al., 2000; Rejula et al., 2003). A survey published in the Australian Veterinary Journal (Anonymous, 2002) shows that the main stress factors are: relationships with angry or sad clients, the recovery of amounts of money not paid by clients, euthanasia and working conditions, especially working time problems. According to Gardner and Hini (2006), the main stressors are gender related. Women are more likely to report job stressors in relation with job demands, interpersonal interactions with employers, peers and clients or the need to keep up technical skills and knowledge. Job stressors for men are more particularly related to income, finances and career prospects.

Together, all these factors can lead to impaired health and performance.

There have been, however, few formal studies on job strain and burnout in veterinary surgeons and the rare studies available present contradictory results. Most of the literature reports moderate stress levels among respondents (Anonymous, 2002; Gardner and Hini, 2006). In one study, Rejula et al. (2003) reported that $73 \%$ of the veterinary surgeons perceived feeling 'rather' or 'very stressed'. Results are more consistent for burnout. Rejula et al. (2003) reported that only $1.7 \%$ of veterinary surgeons demonstrated severe symptoms of burnout. Elkins and Elkins (1987) presented similar results. In the literature, stress is also often examined through mental and physical outcomes. Suicide among veterinary surgeons (Jeyaretnam et al., 2000; Bartram and Baldwin, 2008), for example, has been used as an indicator of the high stress level in this occupation. Substance abuse is also frequently observed in veterinary surgeons (Jeyaretnam et al., 2000; Rejula et al., 2003). The studies reported in the literature present the limitation of using non standardised measures of wellbeing outcomes. It is then difficult to compare veterinary surgeons to other occupations.

Concerning gender differences, Gardner and Hini (2006) reported that stress affects mostly young women in small animal practice (mainly because of the relationships with clients in clinical practice). Rejula et al. (2003) demonstrated that $71 \%$ of woman and $77 \%$ of men reported being 'rather stressed' or 'very stressed', mainly (65\%) because of: being on call, administrative duties, insecurity of work, haste in work, heavy workload and unclear job description. Emotional exhaustion was most common among small animals and equine practitioners.

\section{Stress in Belgian veterinary surgeons}

In Belgium, more and more veterinary surgeons are talking about high levels of stress and suicide in their profession. However, the authors have found no scientific research about wellbeing in Belgian veterinary surgeons. Over the last two decades, Belgian bovine practitioners have encountered numerous changes. The profession is an aging one and Belgium will soon face a lack of young bovine veterinary surgeons. Furthermore, a decreasing number of farms has left a large part of the rural economic system under threat. There are also obvious changes within bovine practice itself. These include the increasing responsibility of veterinary surgeons and an increased workload. Aside from the administrative workload associated with bovine practice, the clinical work is also very physical, mainly due to the high number of Caesarian sections performed in the Belgian Blue (BB) breed. Each year, approximately 400,000 BB cattle calve in Belgium, of which almost $99 \%$ are by Caesarian section (F. Rollin, personal communication). This figure does not take into account dystocia in other bovine breeds. In addition, these Caesarian sections are not equally distributed over the course of the year but are concentrated mostly between January and May. In Belgium, around 1,400 veterinary surgeons are involved in rural practice. It is thought that some complete more than 1,000 Caesarian sections a year, on average; the highest number reported is 27 Caesarian sections in 24 hours (F. Rollin, personal communication). The authors believe that this situation is specific to Belgium, as they have not found a similar situation in other European countries.

In the current study, the authors intend firstly to measure levels of job strain, job engagement, burnout and workhome interference in veterinary surgeons using self-reports and questionnaires, and secondly to further identify stressors and work characteristics to propose strategies for alleviating stress. According to the Belgian context described above, bovine practice is compared to small animal and mixed activity as far as outcome variables are concerned. Gender and age categories will also be taken into consideration. A comparative perspective will be used in this study through normative scores for job strain, job engagement and burnout and comparison with other samples of workers for work-home interference. The analysis of the job stress factors will focus on bovine practice. 


\section{Materials and methods}

Job strain, job engagement, burnout and work-home interference measures are considered in this study. Firstly, job engagement and job strain are measured using the 'Positive and Negative Occupational Stress Inventory' (PNOSI, 19 items; Hansez et al., 2004). Eight items assessed job engagement (e.g., "I feel stimulated by my work", "My work gives me a lot of satisfaction") and 11 items assessed job strain (e.g., "I feel overload by what I have to do", "I feel nervous when at work") on a four-level scale from one ("never" or "rarely") to four ("almost always" or "always"). The reliability coefficients for our sample are 0.83 and 0.84 , respectively. Normative scores are available. A moderate level of job strain/job engagement can vary from 40 to 60 , with a mean equal to 50 . Values higher than 60 characterise severe job strain. Values lower than 40 characterise very low job engagement.

Secondly, the subscale of emotional exhaustion provides a measure of burnout (Maslach et al., 1996). Burnout is a concept that consists of three dimensions: emotional exhaustion, depersonalisation and lack of personal accomplishment (Maslach, 1982). Practically, the use of the subscale of emotional exhaustion alone (nine items) appears to be a valid measure of professional burnout (Cordes and Dougherty, 1993; Lee and Ashforth, 1996). The subject is asked to answer each item on a scale from one ("never") to seven ("every day"). The level of burnout can vary between nine and 63 with a low level when the score varies from nine to 17 , a moderate level from 18 to 29 and values higher than 29 characterising severe burnout. The reliability coefficient in this sample is 0.89 .

Finally, the 'Survey Work-home Interaction Nijmegen' (SWING, 27 items) is used to measure four types of work-home interaction: (1) negative WHI, referring to a situation in which negative load effects built up at work hampering functioning at home (nine items); (2) negative HWI, referring to negative load effects developed in the home domain that impede functioning at work (six items); (3) positive WHI, defined as positive load effects built up at work that facilitate functioning at home (six items); and, (4) positive HWI, occurring when positive load effects developed at home facilitate functioning at work (six items). The reliability coefficients in our sample are $0.88,0.79,0.80$ and 0.84 , respectively. There are four response categories: "never" (0), "sometimes" (1), "often" (2) and "always" (3). A scale mean for each of the four WHI-scales is calculated. As far as job stress factors are concerned, the Veterinary Stress Inventory (VSI, 45 items) (Biron, O. [2006]. Stress in veterinary surgeons. Unpublished dissertation, University of Liège, Belgium) has been developed for the purpose of this study. Items were created on the basis of results from preliminary interviews with veterinary surgeons and a review of the literature, especially the questionnaire developed by Cooper et al. (1989), to measure stressful job situations among general practitioners. Examples include: "phone calls during the night and early in the morning", "administrative formalities because of the new policy about medicines" or "euthanasia requests for non-suffering patients". The full list of items is available from the first author. The response format is a four-point Likert scale from "never a cause of stress" to "always a cause of stress". This quantitative methodology was completed by an open question in which participants were asked to freely describe a maximum of three problematic events that they encounter in their daily work activities.

In collaboration with the Belgian professional union of veterinary surgeons, these questionnaires were sent to the 2,700 French-speaking veterinary surgeons through the Belgian journal 'Veterinaria'. This procedure did not give the opportunity for a reminder.

\section{Statistical analysis}

In the first instance, analyses of variance were performed to test for differences in weekly working hours according to the type of activity and age categories. A t-test was used to compare the difference in weekly working hours for men and women.

Descriptive statistics including means and standard deviations are presented for job strain, job engagement, burnout and work-home interference. According to standardised scores, the three first outcome variables are categorised in small, medium or high level of score. Comparisons of these three variables, according to the type of activity, gender and age categories, were performed using multivariate analyses of variance (MANOVA). All paired comparisons were evaluated using the Tukey posthoc test.

As regards work-home interference, paired sample t-tests were used to compare the differences between subscales of work-home interference (WHI). In order to account for multiple comparisons, the authors used the Bonferroni correction (Miller, 1981, pp. 6-8), which sets the alpha value for the entire set of ${ }^{n}$ comparisons equal to $\alpha_{\text {by }}$ taking the alpha value for each comparison equal to $\alpha / n$ i.e., in this case $\mathrm{P}<$. 05/6 = 0.008. A t-test was also used to compare Belgian veterinary surgeons to either a Belgian/ Luxembourg or a Dutch worker sample $(n=254$ including a large variety of occupations from psychologists, shopkeepers to hotel and bank employees and $n=1,857$ including employees in the electronic industry, employees from the Dutch Postal Office, employees from a financial consultancy firm, employees from a Dutch taxing company and teachers, respectively). Comparisons of the four subscales of workhome interference according to the type of activity, gender and age categories were also performed using MANOVA. In MANOVA, the underlying mathematical foundations depend upon certain assumptions: homogeneity of variances, equality of covariance matrices and normality. These assumptions have been checked with, respectively, Levene's test, Box's test and Shapiro-Wilk's test. All Levene's tests are non significant except for the negative home-work interference subscale when comparing the type of activity. As all Box's tests were non significant, the observed covariance matrices of the dependent variables are equal across groups. Concerning Shapiro-Wilk's tests, the results are significant except for the negative work-home 
Table 1: The spectrum of activity, gender, age, work and maritial status and number of children of the sample population $(\mathrm{n}=216)$

\begin{tabular}{|l|l|r|l|}
\hline & & $n$ & $\%$ \\
\hline Main activity & Rural practitioners & 63 & 25.9 \\
\hline & Small animal practitioners & 111 & 45.7 \\
\hline Gender & Mixed practitioners & 42 & 17.3 \\
\hline Age & Male & 163 & 75.5 \\
\hline & Female & 53 & 24.5 \\
\hline & $36-45$ & 40 & 18.5 \\
\hline Work status & $46-55$ & 77 & 35.6 \\
\hline Marital status & More than 56 years old & 30 & 13.9 \\
\hline & Freelance & 116 & 53.7 \\
\hline & In association with practice & 100 & 46.3 \\
\hline & Single & 21 & 9.7 \\
\hline & Married & 174 & 80.6 \\
\hline & Divorced & 17 & 7.9 \\
\hline & Widowed & 3 & 1.4 \\
\hline & Unknown & 1 & 0.5 \\
\hline Number of children & 0 & 28 & 13 \\
\hline & 1 & 27 & 12.5 \\
\hline & 2 & 83 & 38.4 \\
\hline & 3 or more & 34.3 \\
\hline & Unknown & 1.9 \\
\hline
\end{tabular}

interference subscale. However, some authors suggest that departures from normality have only a slight effect on the Type I error rate (Zar, 1999, p320).

As regards the Veterinary Stress Inventory, factor analyses are not relevant due to the small sample size. Then, descriptive statistics for the 10 items with the highest means within each type of activity will be presented. Item analyses using multivariate technique were performed for the comparisons of the 10 items according to the type of activity. For all statistical analyses in this paper, significance was assumed for a $P$ value less than 0.05 .

The problematic situations were classified in a taxonomy created in collaboration with the research pool Preventagri (Bossut and De Keyser, 2002) and a first intuitive scrolling through the data. Using this method, situations were sorted out and given absolute and relative statistical frequencies.

\section{Results}

Two hundred and forty-three questionnaires were returned and included in the analyses. The total percentage return rate was $9 \%$. As regards main activity, $25.9 \%$ of the sample were rural practitioners. Almost half of the sample consisted of small animal veterinary surgeons and $17.3 \%$ had a mixed activity. The remaining participants were involved in specific activities such as teaching, scientific research or the civil services, thus the final sample consisted of 216 practitioners involved either in rural, small animal or mixed activity practice (Table 1 ). Most of them were male, whilst $24.5 \%$ were female. Most women were involved in small animal practice while most men were bovine or mixed practitioners $\left(\chi^{2}[2 \mathrm{df}]=52.00 ; \mathrm{P}<0.001\right)$. Sixty-seven percent were aged between 36 and 55, while $18.5 \%$ were aged between 25 and 35 . The veterinary surgeons older than 56 years represented $13.9 \%$ of the sample. One half of the respondents worked alone as freelance practitioners, whereas the other half worked in association with a practice. The majority were married or had at least one child $(85.2 \%, \mathrm{n}=184)$.

An important variable was long working hours. The mean working hours for respondents were $54.27 \pm 18.75$ hours, which is a similar figure to that reported by Phillips et al. (2001). One veterinary surgeon out of four worked more than 60 hours a week. One veterinary surgeon out of two worked between 40 and 60 hours a week. Bovine and mixed practitioners $(63.13 \pm 18.39$ and $59.70 \pm 17.85$ respectively) worked more hours a week than small animal practitioners $(48.03 \pm 16.96), F(2,192)=15.16, P<0.001$. In the same way, men $(58.21 \pm 17.53)$ worked more hours a week than women $(42.53 \pm 17.45), \mathrm{t}(193)=-5.42, \mathrm{P}<0.001$. The age variable was not significant with respect to working hours, $F(3,191)=0.88, P=0.45$.

The mean job engagement level in veterinary surgeons was $54.06 \pm 8.89$. This result corresponds to $95.4 \%$ of the current sample that reported a normal or high amount of job engagement. Only $3.7 \%$ of veterinary surgeons did not feel stimulated at work. The mean job strain level in veterinary surgeons was $52.19 \pm 8.15$, which is similar to other working populations. These results correspond to $14.8 \%$ of the current sample that reported a high level of job strain. Moreover, $14.4 \%$ of the group was classed as suffering from high burnout (Table 2).

The multivariate analysis of variance of these three wellbeing variables performed to compare the type of activity was significant; Wilks' lambda $=0.93, F(6,410)=2.41$, $P=0.03$. More specifically, job engagement and job strain showed significant results; $F(2,207)=3.38, P=0.04$ and $F(2$, 207) $=3.84, P=0.02$, respectively. The burnout level did not change across the three types of activity; $F(2,207)=2.34$,

Table 2: Mean (standard deviation) job strain, job engagement and burnout levels in veterinary surgeons $(\mathrm{n}=216)$ according to the type of activity, gender and age

\begin{tabular}{|c|c|c|c|c|c|c|c|c|c|c|c|c|c|c|c|}
\hline & & & & Level & & & Type of a & tivity & & Gender & & Age ca & egories & & \\
\hline & Min & Max & $\begin{array}{l}\text { Mean } \\
\text { (SD) }\end{array}$ & $\begin{array}{l}\text { Low } \\
\%(n)\end{array}$ & $\begin{array}{l}\text { Med. } \\
\%(n)\end{array}$ & $\begin{array}{l}\text { High } \\
\%(n)\end{array}$ & Bovine & $\begin{array}{l}\text { Small } \\
\text { animals }\end{array}$ & Mixed & Female & Male & $25-35$ & $36-45$ & $46-55$ & $56+$ \\
\hline $\begin{array}{l}\text { Job } \\
\text { engagement }\end{array}$ & 31.35 & 74.70 & $\begin{array}{l}54.06 \\
(8.89)\end{array}$ & $\begin{array}{l}3.7 \\
(8)\end{array}$ & $\begin{array}{l}71.3 \\
(154)\end{array}$ & $\begin{array}{l}24.1 \\
(52)\end{array}$ & $\begin{array}{l}52.09 * \\
(8.49)\end{array}$ & $\begin{array}{l}55.66 * \\
(8.95)\end{array}$ & $\begin{array}{l}53.35 \\
(8.91)\end{array}$ & $\begin{array}{l}56.55 * \\
(8.06)\end{array}$ & $\begin{array}{l}53.41 * \\
(9.06)\end{array}$ & $\begin{array}{l}53.63 \\
(7.51)\end{array}$ & $\begin{array}{l}55.59 \\
(9.26)\end{array}$ & $\begin{array}{l}53.97 \\
(8.79)\end{array}$ & $\begin{array}{l}51.74 \\
(9.75)\end{array}$ \\
\hline Job strain & 28.04 & 75.12 & $\begin{array}{l}52.19 \\
(8.15)\end{array}$ & $\begin{array}{l}5.6 \\
(12)\end{array}$ & $\begin{array}{l}79.2 \\
(171)\end{array}$ & $\begin{array}{l}14.8 \\
(32)\end{array}$ & $\begin{array}{l}53.14 \\
(8.20)\end{array}$ & $\begin{array}{l}50.64 * \\
(8.17)\end{array}$ & $\begin{array}{l}54.24 * \\
(6.97)\end{array}$ & $\begin{array}{l}49.69 * \\
(8.36)\end{array}$ & $\begin{array}{l}52.84 * \\
(7.84)\end{array}$ & $\begin{array}{l}52.76 \\
(6.62)\end{array}$ & $\begin{array}{l}52.50 \\
(8.23)\end{array}$ & $\begin{array}{l}52.03 \\
(7.26)\end{array}$ & $\begin{array}{l}50.18 \\
(10.83)\end{array}$ \\
\hline Burnout & 9.00 & 63.00 & $\begin{array}{l}22.22 \\
(9.47)\end{array}$ & $\begin{array}{l}31 \\
(67)\end{array}$ & $\begin{array}{l}51.9 \\
(112)\end{array}$ & $\begin{array}{l}14.4 \\
(31)\end{array}$ & $\begin{array}{l}24.14 \\
(10.00)\end{array}$ & $\begin{array}{l}20.93 \\
(9.20)\end{array}$ & $\begin{array}{l}22.79 \\
(9.09)\end{array}$ & $\begin{array}{l}19.91 * \\
(8.49)\end{array}$ & $\begin{array}{l}22.96 * \\
(9.68)\end{array}$ & $\begin{array}{l}22.49 \\
(7.38)\end{array}$ & $\begin{array}{l}22.08 \\
(9.52)\end{array}$ & $\begin{array}{l}22.16 \\
(9.55)\end{array}$ & $\begin{array}{l}22.37 \\
(11.83)\end{array}$ \\
\hline
\end{tabular}

$N B *$ represents significant results $(p<.05)$ for post-hoc tests. 
Table 3: Mean (standard deviation) work-home interference in veterinary surgeons $(n=216)$ according to the type of activity, gender and age

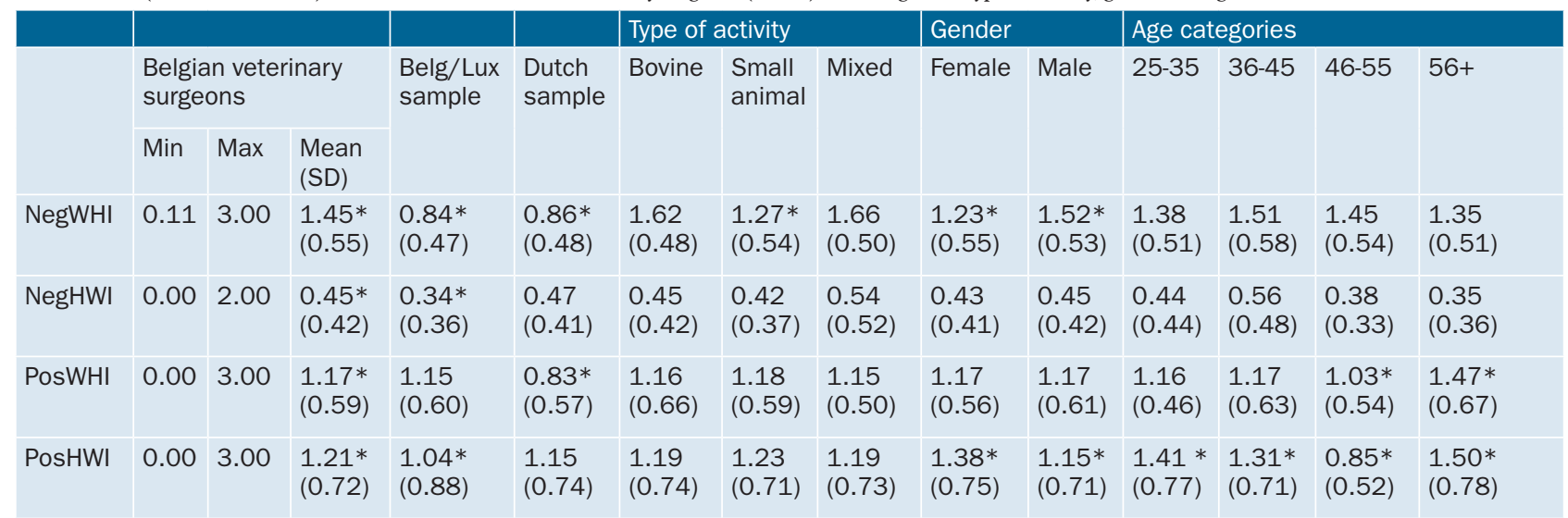

NB: NegWHI = Negative work-home interference; NegHWI = Negative home-work interference; PosWHI = Positive work-home interference; PosHWI = Positive home-work interference. * represents significant results ( $p<.05)$ for post-hoc tests.

$P=0.10$. Tukey HSD post-hoc tests showed that bovine practitioners had a lower level of job engagement than small animal veterinary surgeons $(P=0.04)$, who, in turn, had a lower level of job strain than mixed practitioners $(P=0.04)$ (Table 2). The multivariate analysis of variance of these three wellbeing variables, that compared men and women, was significant (Wilks' lambda $=0.96, F(3$, 206) $=2.78, P=0.04)$. Job engagement was higher among women $(F(1,208)=4.85, P=0.03)$, while men perceived a higher level of job strain and burnout $(F(1,208)=6.03$, $P=0.01$ and $F(1,208)=4.03, P=0.05$, respectively). Finally, the multivariate analysis of variance of the three wellbeing variables performed to compare the age categories was not significant (Wilks' lambda $=0.95, F(9,496.63)=1.18, P=0.30$ ). Results for work-home interference are presented in Table 3. Paired sample t-tests showed that each difference between subscales of work-home interference (WHI) were significant $(P<0.001)$, except between positive work-home interference and positive home-work interference $(t(194)=-$ $0.97, P=0.33$ ). If one considers that $\mathrm{WHI}$ subscales can vary between zero and three, the veterinary surgeons sample did not perceive high work-home interference. However, in comparison to other Belgian and Dutch workers samples, they did perceive significantly more negative work-home interference; $t(213)=16.07, P<0.001$ and $t(213)=15.54$, $P=0.00$, respectively. In comparison to the Belgian sample, veterinary surgeons reported more negative home-work interference $(t(213)=3.77, P<0.001)$ and more positive home-work interference $(t(196)=3.33, P<0.001)$. The result for positive work-home interference was not significantly different $(t(207)=0.51, P=0.61)$. In comparison to the Dutch sample, veterinary surgeons reported less positive work-home interference $(t(207)=8.3, P<0.001)$. Results for negative home-work interference and positive home-work interference were not significantly different; $t(213)=-0.76$, $P=0.45$ and $t(196)=1.17, P=0.24$, respectively.

The multivariate analysis of variance of the four WHI subscales performed to compare the type of activity was significant (Wilks' lambda $=0.88, F(8,374)=3.19, P=0.002$ ). More particularly, negative work-home interference showed a significant result $(F(2,190)=11.89, P<0.001)$ while the other subscales were not significant; $F(2,190)=1.20, P=0.30$, $F(2,190)=0.06, P=0.95, F(2,190)=0.04, P=0.96$, respectively (Table 3). Tukey HSD post-hoc tests show that, compared to small animal practitioners, bovine and mixed practitioners are the most concerned with this negative work-home interference $(P<0.001$ and $P=0.001$, respectively). The multivariate analysis of variance of the four WHI subscales performed to compare men and women was significant; Wilks' lambda $=0.92, F(4,188)=4.02, P=0.004$. Men perceived more negative work-home interference $(F(1,191)=10.41$, $P=0.001)$, while women perceived more positive homework interference $(F(1,191)=3.74, P=0.05)$. Finally, the multivariate analysis of variance of the four WHI subscales performed to compare age categories was also significant (Wilks' lambda $=0.82, F(12,492.4)=3.11, P<0.001$ ). The negative home-work interference subscale was significant $(F(3,189)=2.82, P=0.04)$. The two positive subscales were also significant $(F(3,189)=3.61, P=0.01$ for positive workhome interference and $F(3,189)=8.68, P<0.001$ for positive home-work interference). Tukey HSD post-hoc tests showed that Belgian veterinary surgeons aged between 46 and 55 felt less positive interference from work to home and home to work.

The open question allowed 575 problem-situations to be collected: 175 amongst bovine practitioners, 289 amongst small animal practitioners and 111 amongst mixed practitioners. For bovine practitioners, the three main sources of stress reported were: (1) client relations (farmers in this case) $(30 \%, \mathrm{n}=52)$ mainly through late or unpaid invoices and lack of respect; (2) working time management $(26 \%, \mathrm{n}=45)$, more specifically, simultaneous emergencies and on duty situations; and, (3) risks associated with this occupation $(13 \%, \mathrm{n}=23)$, such as heavy working conditions and difficulties in diagnosis (Table 4). These three main categories of potential sources of stress were also relevant, in the same order, for small animal and mixed practitioners: (1) $34.6 \%, \mathrm{n}=100 ;$ (2) $28 \%, \mathrm{n}=82$; (3) $14.5 \%, \mathrm{n}=42$ and (1) $35 \%$; $\mathrm{n}=39$; (2) $32 \%, \mathrm{n}=35$; (3) $8 \%$; $\mathrm{n}=9$, respectively. There was no significant statistical difference in the three main sources of stress by activity status $(\chi 2(4)=3.15$, P $>0.05)$. The problematic situations encountered by small 
Table 4: Problematic situations (total $n=175$ ) encountered by bovine practitioners

\begin{tabular}{|c|c|c|c|}
\hline Category & $\%(n)$ & Sub-category & $\%(n)$ \\
\hline \multirow[t]{5}{*}{ Client relations } & \multirow[t]{5}{*}{$30(52)$} & Unpaid or late invoices & $48(25)$ \\
\hline & & Lack of respect, careless, ungratefulness & $21(11)$ \\
\hline & & Unspecified & $13(7)$ \\
\hline & & Short deadline requirement & $10(5)$ \\
\hline & & Constraint about optimal result & $8(4)$ \\
\hline \multirow[t]{8}{*}{ Time management } & \multirow[t]{8}{*}{$25.7(45)$} & Simultaneous emergencies, during consulting hours & $51(23)$ \\
\hline & & Continuous availability, night work, on duty situations & $25(11)$ \\
\hline & & Unspecified & $11(5)$ \\
\hline & & Irregular work throughout year & $5(2)$ \\
\hline & & Fake emergencies & $2(1)$ \\
\hline & & Phone harassment & $2(1)$ \\
\hline & & Night calls & $2(1)$ \\
\hline & & Shiftwork & $2(1)$ \\
\hline \multirow[t]{4}{*}{ Occupational risks } & \multirow[t]{4}{*}{$13(23)$} & Heavy working conditions & $39(9)$ \\
\hline & & Difficult diagnosis/ treatment & $35(8)$ \\
\hline & & Therapeutic failure & $17(4)$ \\
\hline & & Disappointing financial incomes & $9(2)$ \\
\hline \multirow[t]{6}{*}{ Relations to co-workers } & \multirow[t]{6}{*}{$10.3(18)$} & Unfair competition & $45(8)$ \\
\hline & & Misunderstanding from administration/ lawmakers & $23(4)$ \\
\hline & & Unspecified & $11(2)$ \\
\hline & & Conflicts between associates & $11(2)$ \\
\hline & & Misunderstanding/ management between co-workers & $5(1)$ \\
\hline & & Food agency & $5(1)$ \\
\hline Administrative workload & $8(14)$ & & \\
\hline \multirow[t]{3}{*}{ Quantitative workload } & \multirow[t]{3}{*}{$4(7)$} & Lack of time for professional improvement & $44(3)$ \\
\hline & & Unspecified & $28(2)$ \\
\hline & & Replacement/ work assistance & $28(2)$ \\
\hline \multirow[t]{3}{*}{ Responsibilities } & \multirow[t]{3}{*}{$3(6)$} & Unsatisfied clients bringing the vet into action & $50(3)$ \\
\hline & & Dual-responsibility: service and control & $33(2)$ \\
\hline & & Unspecified & 17 (1) \\
\hline
\end{tabular}

NB: 10 non relevant situations were not included in the analysis.

stressors and work characteristics. Bovine practice was compared to small animal and mixed practice.

The current study revealed a moderate level of job strain in Belgian veterinary surgeons, no higher than in other professional groups. This is surprising when the inherent stressful working conditions described in the introduction, i.e., increasing responsibility of veterinary surgeons and the increasing workload, are taken into consideration. Different authors (Payne, 1987; Karasek, 1995) have found that stress levels can be mitigated by having high authority and high satisfaction in the job. The current study concurs with this statement. Most of the veterinary surgeons sample showed high job engagement which, in turn, may have moderated the job strain levels.

Another important result concerns burnout: more than $15 \%$ of the veterinary surgeons sample reported a high level of emotional exhaustion. This result is alarming, according to other studies about burnout in veterinary surgeons (Elkins and Elkins, 1987; Rejula et al., 2003). The results are similar to those observed in anaesthetists by Nyssen et al. 
Table 5: Top 10 stressors (highest means) for each type of activity

\begin{tabular}{|c|c|c|c|c|c|c|}
\hline & \multicolumn{3}{|l|}{ Rank (Mean) } & \multirow{2}{*}{$\begin{array}{l}F(2, \\
188)\end{array}$} & \multirow[t]{2}{*}{$\mathrm{P}$} & \multirow[t]{2}{*}{ Post-hoc } \\
\hline & $\begin{array}{l}\text { Bovine } \\
\text { Practice (1) }\end{array}$ & $\begin{array}{l}\text { Small animal } \\
\text { Practice (2) }\end{array}$ & $\begin{array}{l}\text { Mixed } \\
\text { Practice (3) }\end{array}$ & & & \\
\hline Administrative formalities because of new medicines policy & $1(3.22)$ & $5(2.66)$ & $1(3.15)$ & 6.66 & 0.00 & $2<1$ and 3 \\
\hline Impact of job constraints on family life & $2(2.94)$ & $4(2.72)$ & $2(2.97)$ & 2.11 & 0.12 & NA \\
\hline Recovery of amounts of money due from customers & $3(2.88)$ & $2(2.81)$ & $4(2.82)$ & 0.08 & 0.92 & NA \\
\hline Interruption of family life by phone calls & $4(2.76)$ & $3(2.75)$ & $3(2.90)$ & 0.43 & 0.65 & NA \\
\hline Impact of job constraints on social life & $5(2.72)$ & $-(2.47)$ & $5(2.67)$ & 3.33 & 0.04 & NA \\
\hline Lack of gratefulness by customers & $6(2.75)$ & $-(2.46)$ & $7(2.69)$ & 1.23 & 0.29 & NA \\
\hline Long working hours & $7(2.62)$ & $-(2.39)$ & $-(2.49)$ & 1.05 & 0.35 & NA \\
\hline Time sharing between spouse and patients & $8(2.70)$ & $9(2.57)$ & $9(2.72)$ & 0.53 & 0.59 & NA \\
\hline Phone calls during the night and early in the morning & $9(2.60)$ & $1(3.15)$ & $6(2.72)$ & 6.44 & 0.00 & $2>1$ and 3 \\
\hline Unrealistic expectations from customers & $10(2.56)$ & $-(2.27)$ & $-(2.36)$ & 2.05 & 0.13 & NA \\
\hline Administrative constraints due to tax liability & $-(2.40)$ & $6(2.58)$ & $-(2.56)$ & 0.44 & 0.65 & NA \\
\hline Euthanasia requests for non-suffering patients & $-(1.88)$ & $7(2.63)$ & $-(1.74)$ & 13.50 & 0.00 & $2>1$ and 3 \\
\hline Emergency calls during consulting hours & $-(2.32)$ & $8(2.62)$ & $8(2.67)$ & 1.84 & 0.16 & NA \\
\hline Follow up of difficult cases & $-(2.44)$ & $10(2.48)$ & $-(2.41)$ & 0.11 & 0.90 & NA \\
\hline $\begin{array}{l}\text { Loss of clients profitable to another veterinary surgeon } \\
\text { (competition) }\end{array}$ & $-(2.36)$ & $-(2.46)$ & $10(2.49)$ & 0.24 & 0.79 & NA \\
\hline
\end{tabular}

NB: The multivariate analysis of the 15 items performed to compare the type of activity was significant, Wilks' lambda $=.61, F(30,348)=3.27, P=.000$.

(2003). These professionals, like veterinary surgeons, seem to enjoy and feel stimulated by their job, but find certain working conditions difficult to cope with. For veterinary surgeons, in the context described above, administrative requirements, difficult relationships with clients and working time constraints can explain this feeling of emotional exhaustion.

This result concerning burnout can be further explained by a much higher negative interference from work to home than what the authors found in other working populations. This holds especially true for bovine and mixed practitioners. The unpredictability of the veterinary working schedule leads all practitioners, but especially bovine and mixed practitioners, to be on stand-by regularly. This variable 'work pace' does not fit with family life. In addition, veterinary surgeons have to be easily reachable by phone and most of the time they do not feel free, especially if they are self-employed and isolated. Flexible schedules in agriculture force veterinary surgeons to deal with flexible planning. Their working time does not allow them to fulfil elementary family roles, which is perceived as difficult by practitioners, and probably even more so by their spouse and children.

There are few other differences in the current sample concerning the type of activity. Bovine practitioners report less job engagement than small animal practitioners. Small animal veterinary surgeons have a lower level of job strain than mixed practitioners. The level of burnout is the same across the three types of activity. This result does not concur with the results reported by Rejula et al. (2003) that, among veterinary surgeons, small animal and equine practitioners are the most affected by emotional exhaustion.

The comparison of age also gives some unexpected results. Job engagement, job strain and burnout were not different according to the age of the veterinary surgeon. The authors had thought that even if a practitioner was engaged and committed in the early years of his or her career, their work might have become monotonous and not status-enhancing. However, this was not confirmed in the results.

The present study has its limitations. The response rate in our study was very small, mainly because it was not possible for the authors to send a reminder to potential respondents. The authors could also argue that only veterinary surgeons having more time to answer (and thus a lower workload) have participated in the survey. This could also explain why, despite an alarming context, the results do not confirm a high risk situation in veterinary surgeons as far as wellbeing is concerned. However, the size of the sample was acceptable for the statistical analyses performed on the data. Moreover, the study is focused on French speaking veterinary surgeons working in Belgium and there are few studies in the literature with which to compare the results. It would be interesting to replicate this study in other countries in a cross-cultural perspective.

\section{Conclusion}

In this present study, Belgian veterinary surgeons were involved in a survey about stressors and work characteristics, job strain, job engagement, burnout and work-home interference. The main results were a moderate level of job strain together with a high job engagement, a percentage of high burnout in the sample higher than $15 \%$ and a much higher negative interference from work to home than what was found by the authors in other working populations, especially for bovine and mixed practitioners. Some interesting new aspects emerged from the results. First, job engagement is a key variable in the way veterinary surgeons perceive their work situation. This is in line with the stress literature which has recently proposed a new theoretical model: the 'Job Demands- 
Resources Model' (Schaufeli and Bakker, 2004). This model refers to two processes, one linked with the positive (motivational process, i.e., job engagement), and the other with the negative (health impairment process, i.e., burnout) aspects of wellbeing, making this phenomenon easier to understand. Second, results about work stressors in the veterinary profession are consistent all through research, including this study: long working hours, excessive workload, working time problems, ethical problems and euthanasia, relationships with clients, occupational risks, diseases related to animal care, uncomfortable working positions and recovery of amounts of money not paid by clients. Third, negative work-home interference was used for the first time in veterinary research. In this study, bovine and mixed practitioners are particularly at risk, mainly because of the unpredictability of the veterinary working schedule and the flexible planning according to phone calls and stand-by duty. For these three new aspects, a sensitisation about job resources, such as external support for the planning, some extra help for administrative purposes and good communications skills, may be effective for improving wellbeing at work in the veterinary profession.

Bartram and Baldwin (2008) also reported that several countries such as the UK, US, Canada and Norway have already developed stress management interventions, including a 24-hour peer-support telephone helpline service, programmes of mental health seminars in veterinary schools or training modules on professional key skills. In Belgium, such a helpline service for farmers is organised by the Agricall Walloon Association and the idea was recently extended to veterinary practitioners. Bartram and Baldwin (2008) also suggest incorporating training in the use of effective coping strategies for alleviating stress, burnout and negative work-home interference.

In conclusion, the cross-cultural perspective could be interesting in terms of sensitisation and publication of best practices within the world concerning for example administrative requirements, training programmes in terms of communication skills or counselling for a better worklife balance among veterinary surgeons.

\section{References}

Anonymous. (2002). Survey details stress factors that influence Australian vets. Australian Veterinary Journal 80: 522-524.

Arluke, A. (1991). Coping with euthanasia: a case study of shelter culture. Journal of the American Veterinary Medicine Association 198: 1176-1180.

Bartram, D.J. and Baldwin, D.S. (2008). Veterinary surgeons and suicide: influences, opportunities and research directions. Veterinary Record 12: 36-40.

Bledsoe, W.D. (1991). Comments on stress and burnout articles. Journal of American Veterinary Medical Association 198: 2032-2036.

Bossut, M. and De Keyser, V. (2002). Exploratory research about psychosocial risks in Walloon agriculture. DOCUP federal 2000.01.14. Liège, Belgium: University of Liège.

Cooper, C.L., Rout, U. and Faragher, B. (1989). Mental health, job satisfaction, and job stress among general practitioners. British Medical Journal 298: 366-370.
Cordes, C.J. and Dougherty, T.W. (1993). A review and an integration of research on job burnout. Academy of Management Review 18: 621-656. De Keyser, V. and Hansez, I. (1996). Vers une perspective transactionnelle du stress au travail: Pistes d'évaluations méthodologiques. Les Cahiers de Médecine du Travail 33: 133-144.

Elkins, A.D. and Elkins, J.R. (1987). Professional burnout among U.S. veterinarians: how serious a problem? Veterinary Medicine 82: 1245-1250. Firth, H. and Britton, P. (1989). Burnout, absence and turnover among British nursing staff. Journal of Occupational Psychology 62: 55-59. Gabel, C. and Gerberich, G. (2001). Risk factors among veterinarians. Veterinary Injury Risk 13: 80-86.

Gardner, D.H. and Hini, D. (2006). Work-related stress in the veterinary profession in New Zealand. New Zealand Veterinary Journal 54: 119-124. Garrett, D.K. and McDaniel, A.M. (2001). A new look at nurse burnout: the effects of environmental uncertainty and social climate. Journal of Nursing Administration 31: 91-96.

Geurts, S.A.E., Taris, T.W., Kompier, M.A.J. , Dikkers, J.S.E., Van Hooff, M.L.M and Kinnunen, U.M. (2005). Work-home interaction from a work psychological perspective: Development and validation of a new questionnaire, the SWING. Work and Stress 19 (4): 319-339.

Hansez, I., Grisard A., and De Keyser, V. (2004). 'Organizational changes, job strain among employees and client satisfaction: elaboration of the flexihealth concept, PS/12/29 - 1999/2003, Internal research report, University of Liège, Belgium.

Houston, D. and Allt, S.K. (1997). Psychological distress and error making among junior house officers. British Journal of Health in Psychology 2: 141151.

Jeyaretnam, J., Jones, H. and Philips, M. (2000). Disease and injury among veterinarians. Australian Veterinary Journal 78: 625-629.

Karasek, R.A. (1979). Job demands, job decision latitude and mental strain: Implication for job redesign. Administrative Science Quaterly 24: 285-308. Klein, G.T. (1996). The effects of acute stressors on decision making. In: Stress and Human Performance. pp 49-88. Edited by J.E. Driskell and E. Salas. Mahwah, NJ: Lawrence Erlbaum Associates.

Kogan, L. and McConnell, L. (2001). Veterinary students and psychologic services. Journal of American Veterinary Association 218: 873-875.

Langley, R., Pryor, W. and O'Brien, K. (1995). Health hazards among veterinarians: A survey and review of the literature. Journal Agromed 2: 23-52.

Lazarus, R.S. (1995). Psychological stress in the workplace. In: Occupational stress: a handbook. pp 3-14. Edited by R. Crandall and P.L. Perrewé. Bristol: Taylor \& Francis.

Lee, R.T. and Ashforth, B.E. (1995). A meta-analytic examination of the correlates of the three dimensions of job burnout. Journal of Applied Psychology 81: 123-133.

Mackay, C.J. and Cooper, C.L. (1987). Occupational stress and health: some current issues. In: International Review of Industrial and Organizational Psychology. pp 167-199. Edited by C.L. Cooper and I.T. Robertson. Chichester, UK : John Wiley \& Sons Ltd.

Maslach, C. (1982). Burnout : the cost of caring. Englewoods Cliffs, NJ: Prentice-Hall.

Maslach, C., Jackson, S.E. and Leiter, M.P. (1996). Maslach Burnout Inventory, $3^{\text {rd }}$ ed. Palo Alto, CA: Consulting Psychologists Press.

Meyer, J.P. and Allen, N.J. (1997). Commitment in the workplace. Thousand Oaks, CA: Sage Publications.

Miller, R. G. (1981) Simultaneous statistical inference (2nd ed.). New York: Springer Verlag.

Myers, H.L. and Myers, L.B. (2004). 'It's difficult being a dentist': stress and 
health in the general dental practitioner. British Dental Journal 197: 89-93. Nyssen, A.S., Hansez, I., Baele, P., Lamy, M. and De Keyser, V. (2003). Occupational stress and burnout in anaesthesia. British Journal of Anaesthesia 90: 1-5.

Payne, R. (1987). Stress in surgeons. In: Stress in Health Professionals. pp 89-106. Edited by R. Payne and L.F. Cozens. Chichester, UK: John Wiley \& Sons Ltd.

Phillips, D., Morrison, C. and Campbell, N.J. (2001). Same profession, different career: A study of men and women in veterinary medicine. In: Advances in psychology research. Volume 5, pp 1-53. Edited by F.H. Colombus. New York: Hardcover.

Poole, A. (1998). Survey of occupational hazards in companion animal practices. Journal of Veterinary Medical Association 212: 1386-1388.

Rejula, K., Rasanen, K., Hamalainen, M., Juntunen, K., Lindbohm, M.L., Taskinen, H., Bergbom, B. and Rinta-Jouppi, M. (2003). Work environment and Occupational Health of Finnish Veterinarians. American Journal of Industrial Medicine 44: 46-57.

Revicki, D. and May, H.J. (1989). Organizational characteristics, occupational stress and mental health in nurses. Behavioral Medicine 15: 30-36.

Russell, R.L. (1994). Preparing veterinary students with the interactive skills to effectively work with client and staff. Journal of Veterinary Medical Education Association 21: 40-43.

Sanders, C.R. (1995). Killing with kindness: Veterinary euthanasia and the social construction of personhood. Sociological Forum 10: 195-214.

Schaufeli, W.B. and Bakker, A.B. (2004). Job demands, job resources, and their relationship with burnout and engagement: a multi-sample study. Journal of Organizational Behavior 25: 293-315.

Schneider, B.J. (1996). Euthanasia and the veterinarian. Canadian Veterinary Journal 37: 217-218.

Sparks, K., Cooper, C., Fried, Y. and Shirom, A. (1997). The effect of hours of work on health: A meta analysis review. Journal of Occupational Organizational Psychological 70: 391-408.

Trimpop, R., Austin, E.J. and Kirkcaldy, B.D. (2000). Occupational and traffic accidents among veterinary surgeons. Stress Medicine 16: 243-257.

Zar, J.H. (1999). Biostatistical analysis (fourth edition). New Jersey: Prentice Hall.

Wolfgang, A.P. (1988). Job stress in the health professions: a study of physicians, nurses and pharmacists. Behavioral Medicine 14: 43-47. 